Supporting Information

\title{
BioSTEAM: A Fast and Flexible Platform for the Design, Simulation, and Techno- Economic Analysis of Biorefineries Under Uncertainty
}

\author{
Yoel Cortes-Peña ${ }^{\dagger, \ddagger}$, Deepak Kumar ${ }^{\ddagger, \S}$, Vijay Singh ${ }^{\ddagger} »$, Jeremy S. Guest $^{*,+, \neq}$
}

+ Department of Civil and Environmental Engineering, University of Illinois at UrbanaChampaign, 3221 Newmark Civil Engineering Laboratory, 205 N. Mathews Ave, Urbana, IL 61801, USA

₹ DOE Center for Advanced Bioenergy and Bioproducts Innovation (CABBI), University of Illinois at Urbana-Champaign, 1206 W. Gregory Drive, Urbana, IL, 61801, USA

$\S$ Department of Paper and Bioprocess Engineering, State University of New York College of Environmental Science and Forestry, 402 Walters Hall, 1 Forestry Drive, Syracuse, NY, 13210, USA

" Department of Agricultural and Biological Engineering, University of Illinois at UrbanaChampaign, 360 G Agricultural Sciences Building, 1304 W. Pennsylvania Ave, Urbana, IL 61801, USA

Total Pages: 9

\section{Table of Contents:}

Vapor-Liquid Equilibrium Algorithm

Unit Operation Modeling, Design, and Purchase Cost

S4-S7

Accessing Biorefinery Models and Detailed Results

Supporting references

\section{List of Tables:}

Table S1. Unit operation modeling, design, and purchase cost.

\section{List of Figures:}

Figure S1. Iterative algorithm to solve vapor and liquid equilibrium. 


\section{Vapor-Liquid Equilibrium Algorithm}

BioSTEAM can solve vapor liquid equilibrium given molar flow rates and either temperature and pressure, temperature and vapor fraction, temperature and duty, pressure and vapor fraction, or pressure and duty. Before initializing the vapor-liquid equilibrium algorithm, it checks whether the specified conditions lie between the bubble point and dew point. If not, no equilibrium is necessary, and a simple energy balance is performed to achieve the given conditions.

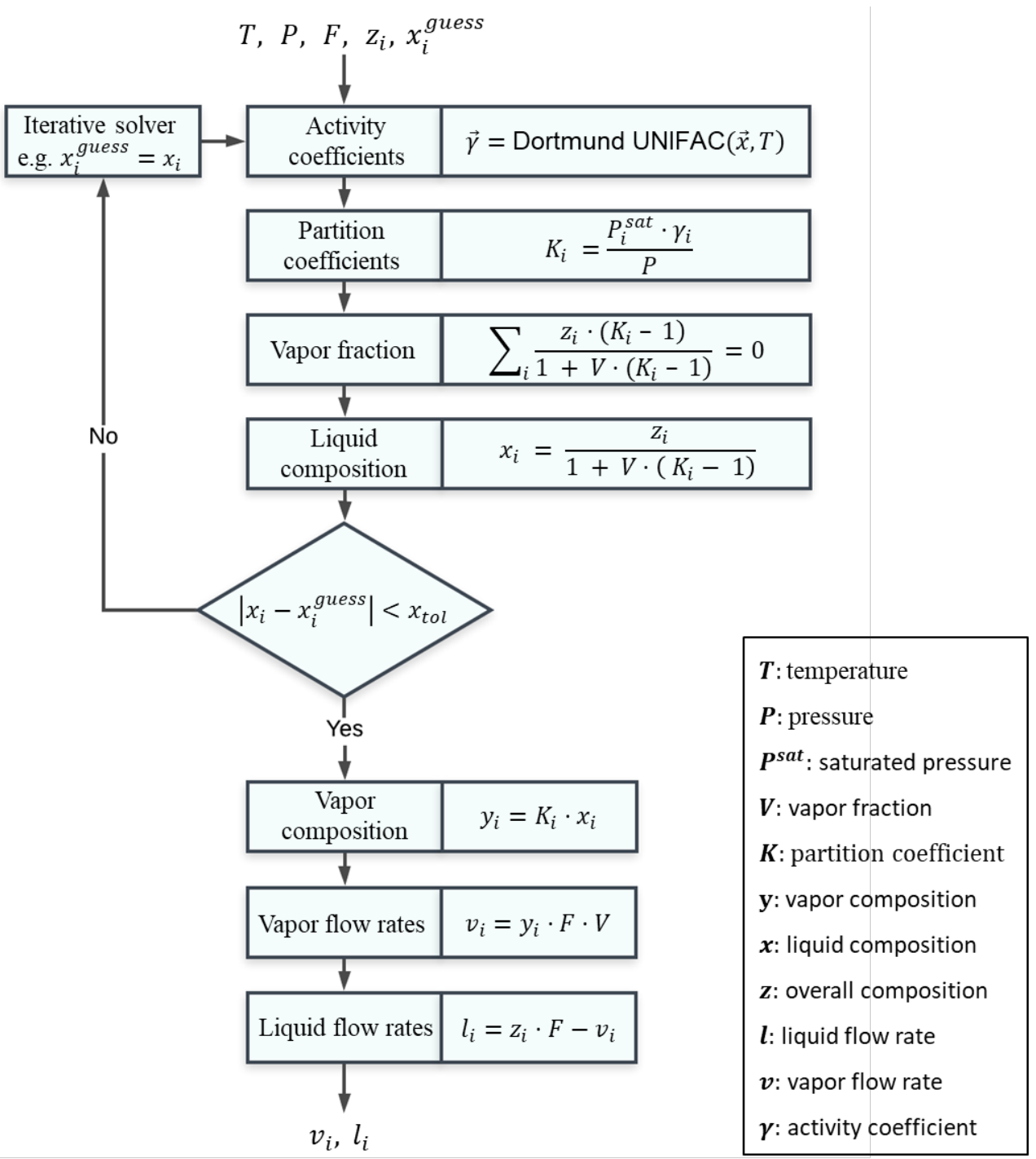

Figure S1. Iterative algorithm to solve vapor and liquid equilibrium. In each iteration, partition coefficients are calculated at a guess liquid phase composition and the new composition is calculated by solving thermodynamic and mass balances. The flowchart presents fixed point iteration, where the next guess composition is the new composition at the given partition coefficient. In BioSTEAM, accelerated Steffensen-Aitken iteration is used to guess the next guess for liquid composition. After the liquid composition converges, vapor and liquid flow rates are solved through a mass balance. 
To solve equilibrium at a specified temperature and pressure, BioSTEAM employs an iterative strategy using the Rashford Rice equation. At a given composition of the liquid phase, partition coefficients can be computed, and the vapor fraction solved by finding the root of the Rashford Rice equation. If only 2 or 3 compounds are in vapor-liquid equilibrium, the vapor fraction is solved analytically. Then, the liquid phase composition is analytically computed at the given vapor fraction and partition coefficients. The evaluated composition can be used as the guess for the next iteration (fixed-point iteration) or as an argument for an accelerated iteration method (e.g. Steffensen-Aitken). The iteration terminates once the guess liquid composition and the computed composition is below a tolerance level. The vapor and liquid flow rates can then be solved through a mass balance. At a higher level, to solve equilibrium given either vapor fraction or duty, BioSTEAM uses a root solver bounded between the dew point and the bubble point to find either the temperature or pressure that satisfies the specification. 


\section{Unit Operation Modeling, Design, and Purchase Cost}

The unit operations for the corn stover biorefinery were modeled, designed, and costed as described in the benchmark design. ${ }^{1}$ For the lipid-cane biorefinery, all essential unit operations are designed and costed using BioSTEAM's algorithms as no correlations were reported in the benchmark study. ${ }^{2}$ Descriptions for unit operation modeling and design algorithms, and the size factors used for capital cost estimation in the lipid-cane biorefinery are detailed in Table S1. Modeling refers to the methods used to calculate mass and energy balances while that design refers to the methods used to calculate the size factors for capital cost estimation. Although not shown in the table, the construction material for all centrifuges and vessels (i.e., mixing and storage tanks, flash vessels, and distillation columns) in the biorefinery is stainless steel (SS304). This selection is based on the techno-economic analysis reports referenced in this study concerning ethanol and biodiesel production. While most unit operation cost correlations for the lipid cane biorefinery were adapted from design textbooks and literature, certain unit operations

were cost based on six tenths rule exponential scaling from the benchmark lipid cane biorefinery. These unit operations include shredders, crushing mills, and magnetic separators. Certain unit operation model separations assuming a certain fraction of chemical components split between output streams. The values of the component splits were back calculated from the benchmark studies. A few unit operations do not have a modeling algorithm as the exit stream is simply equal to the input stream (e.g. tanks and conveyor belts). Unit operations with capital cost size factors based on flow rate do not have a design algorithm as no design is needed to calculate flow rate. Although all heat transfer calculations assume adiabatic conditions, BioSTEAM also presents the option of using a heat transfer efficiency to allow only a fraction of heat to be transferred to the unit operation while the rest is lost to the environment. Considering that high pressure steam is used throughout the biorefineries and heat will be lost in major unit operations such as distillation columns and evaporators, a conservative heat transfer efficiency of $85 \%$ was used for steam utilities. Oliveira, Marques and Parise assumed heat losses in an ethanol-water distillation column to be as high as $10 \% .^{3}$ Although a lower efficiency would allow BioSTEAM's results to be more similar the benchmark models (which may also be using heat transfer efficiencies), a lower efficiency would be overly conservative. A more rigorous assessment of heat losses throughout the biorefinery is required to verify the accuracy of this assumption. 
Table S1. Unit operation modelling, design, and purchase cost correlations.

\begin{tabular}{|c|c|c|c|c|c|c|}
\hline $\begin{array}{c}\text { Unit } \\
\text { Operation }\end{array}$ & BioSTEAM 1.0 & Selection & Modeling & Design & $\begin{array}{c}\text { Capital Cost Size } \\
\text { Factors }\end{array}$ & References \\
\hline Pump & Pump & $\begin{array}{l}\text { Centrifugal single } \\
\text { Centrifugal double } \\
\text { Gear } \\
\text { Metering plunger }\end{array}$ & $\begin{array}{l}\text { Specify outlet } \\
\text { pressure }\end{array}$ & $\begin{array}{l}\text { Based on break and } \\
\text { motor efficiency, } \\
\text { and NEMA standard } \\
\text { motor sizes. }\end{array}$ & $\begin{array}{c}\text { Volumetric flow rate } \\
\text { Head } \\
\text { Power }\end{array}$ & $\begin{array}{l}\text { Seider (2017) } \\
\text { pp. } 450-455 .^{4}\end{array}$ \\
\hline $\begin{array}{l}\text { Heat } \\
\text { Exchanger } \\
\text { (Shell and } \\
\text { tube) }\end{array}$ & $\begin{array}{l}\text { HXutility } \\
\text { HXprocess }\end{array}$ & $\begin{array}{l}\text { Floating head } \\
\text { Fixed head } \\
\text { U tube } \\
\text { Kettle vaporizer } \\
\text { Double pipe }\end{array}$ & $\begin{array}{c}\text { Vapor-liquid } \\
\text { equilibrium } \\
\text { [Specify temperature } \\
\text { or vapor fraction } \\
\text { assuming constant } \\
\text { pressure] }\end{array}$ & $\begin{array}{c}\text { Heat transfer } \\
\text { coefficients based } \\
\text { on typical values for } \\
\text { selected fluids. } \\
\text { Counter current } \\
\text { flow. }\end{array}$ & Heat transfer area & $\begin{array}{c}\text { Seider (2017) } \\
\text { pp. } 316-336, \\
461-463 .^{4}\end{array}$ \\
\hline Flash & $\begin{array}{c}\text { Flash } \\
\text { SplitFlash } \\
\text { PartitionFlash } \\
\text { RatioFlash }\end{array}$ & $\begin{array}{c}\text { Vertical } \\
\text { Horizontal }\end{array}$ & $\begin{array}{l}\text { Vapor-liquid } \\
\text { equilibrium }\end{array}$ & $\begin{array}{l}\text { Heuristic design of } \\
\text { two phase } \\
\text { separators. }\end{array}$ & $\begin{array}{l}\text { Vessel weight, inner } \\
\text { diameter, and length }\end{array}$ & $\begin{array}{l}\text { Seider (2017) } \\
\text { pp. 464-468. }{ }^{4} \\
\text { Svrcek (1993). }{ }^{5}\end{array}$ \\
\hline Distillation & Distillation & Column & McCabe-Thiele & $\begin{array}{c}\text { Based on flooding } \\
\text { velocity and tray } \\
\text { efficiency. }\end{array}$ & $\begin{array}{c}\text { Vessel weight, inner } \\
\text { diameter, and length } \\
\text { Number of trays }\end{array}$ & $\begin{array}{l}\text { Seider (2017) } \\
\text { pp. 392-395, } \\
\text { 464-468. }{ }^{4} \\
\text { Green }(2018) \\
\text { Chapter } 13 .^{6} \\
\text { Duss (2018). }{ }^{7}\end{array}$ \\
\hline Evaporator & MultiEffectEvaporator & $\begin{array}{l}\text { Horizontal tube } \\
\text { Long-tube vertical } \\
\text { Forced circulation } \\
\text { Falling film }\end{array}$ & $\begin{array}{l}\text { Multiple flash vessels } \\
\text { operating at } \\
\text { decreasing pressures. } \\
\text { The vapor fraction of } \\
\text { first evaporator is } \\
\text { solved to achieve the } \\
\text { desired overall vapor } \\
\text { fraction. }\end{array}$ & $\begin{array}{c}\text { Required heat } \\
\text { transfer area is } \\
\text { calculated based on } \\
\text { typical overall heat } \\
\text { transfer coefficients } \\
\text { for evaporator } \\
\text { types. }\end{array}$ & Heat transfer area & $\begin{array}{l}\text { Seider (2017) } \\
\text { pp. } 442,592^{4}\end{array}$ \\
\hline
\end{tabular}


Table S1. Continued...

\begin{tabular}{|c|c|c|c|c|c|c|}
\hline $\begin{array}{c}\text { Unit } \\
\text { Operation }\end{array}$ & BioSTEAM 1.0 & Selection & Modeling & Design & $\begin{array}{c}\text { Capital Cost Size } \\
\text { Factors }\end{array}$ & References \\
\hline $\begin{array}{l}\text { Vacuum } \\
\text { system }\end{array}$ & $\begin{array}{l}\text { vacuum_system } \\
\text { (function) }\end{array}$ & $\begin{array}{l}\text { Steam jet ejector } \\
\text { Liquid ring } \\
\text { Three-stage rotary lobe } \\
\text { Three-stage claw } \\
\text { Screw compressor }\end{array}$ & $\begin{array}{c}\text { Not applicable } \\
\text { (Active when a } \\
\text { unit operation } \\
\text { operates under a } \\
\text { vacuum). }\end{array}$ & $\begin{array}{c}\text { Based on air } \\
\text { leakage into the } \\
\text { vacuumed vessel } \\
\text { and vapor flow } \\
\text { into the vacuum } \\
\text { system. }\end{array}$ & $\begin{array}{l}\text { Vapor mass flow rate } \\
\text { Suction pressure } \\
\text { Volumetric flow rate }\end{array}$ & $\begin{array}{l}\text { Seider (2017) } \\
\text { pp. } 479-480^{4}\end{array}$ \\
\hline $\begin{array}{c}\text { Rotary } \\
\text { vacuum filter }\end{array}$ & RotaryVacuumFilter & Drum & Component split & $\begin{array}{l}\text { Based on typical } \\
\text { filter rate and } \\
\text { sizes. }\end{array}$ & Filter area & $\begin{array}{l}\text { Seider (2017) } \\
\text { pp. } 464-468^{4}\end{array}$ \\
\hline Feeder & ConveyingBelt & Conveying belt & - & - & Volumetric flow rate & $\begin{array}{l}\text { Seider (2017) } \\
\text { pp. } 481-485^{4} \\
\end{array}$ \\
\hline $\begin{array}{c}\text { Solids } \\
\text { centrifuge }\end{array}$ & SolidsCentrifuge & $\begin{array}{c}\text { Continuous scroll solid } \\
\text { bowl }\end{array}$ & Component split & - & Solids mass flow rate & $\begin{array}{l}\text { Seider (2017) } \\
\text { pp. } 481-485^{4}\end{array}$ \\
\hline Clarifier & Clarifier & $\begin{array}{l}\text { Carbon steel } \\
\text { Concrete }\end{array}$ & Component split & $\begin{array}{c}\text { Based on heuristics } \\
\text { for settling area } \\
\text { and height. }\end{array}$ & Surface area & $\begin{array}{l}\text { Seider (2017) } \\
\text { pp. } 481-485^{4}\end{array}$ \\
\hline Cooling tower & CoolingTower & - & $\begin{array}{l}\text { Specify outlet } \\
\text { temperature }\end{array}$ & - & Volumetric flow rate & $\begin{array}{l}\text { Seider (2017) } \\
\text { pp. } 481-485^{4} \\
\end{array}$ \\
\hline $\begin{array}{l}\text { Vibrating } \\
\text { screen }\end{array}$ & VibratingScreen & 3-deck vibrating screen & Component split & $\begin{array}{l}\text { Based on typical } \\
\text { capacities (flow } \\
\text { rate per screen } \\
\text { area) }\end{array}$ & Screen area & $\begin{array}{l}\text { Seider (2017) } \\
\text { pp. } 481-485^{4}\end{array}$ \\
\hline $\begin{array}{c}\text { Liquids } \\
\text { centrifuge }\end{array}$ & LiquidSplitCentrifuge & General separator & Component split & - & Volumetric flow rate & $\begin{array}{c}\text { Apostolakou } \\
(2009)^{8}\end{array}$ \\
\hline
\end{tabular}


Table S1. Continued...

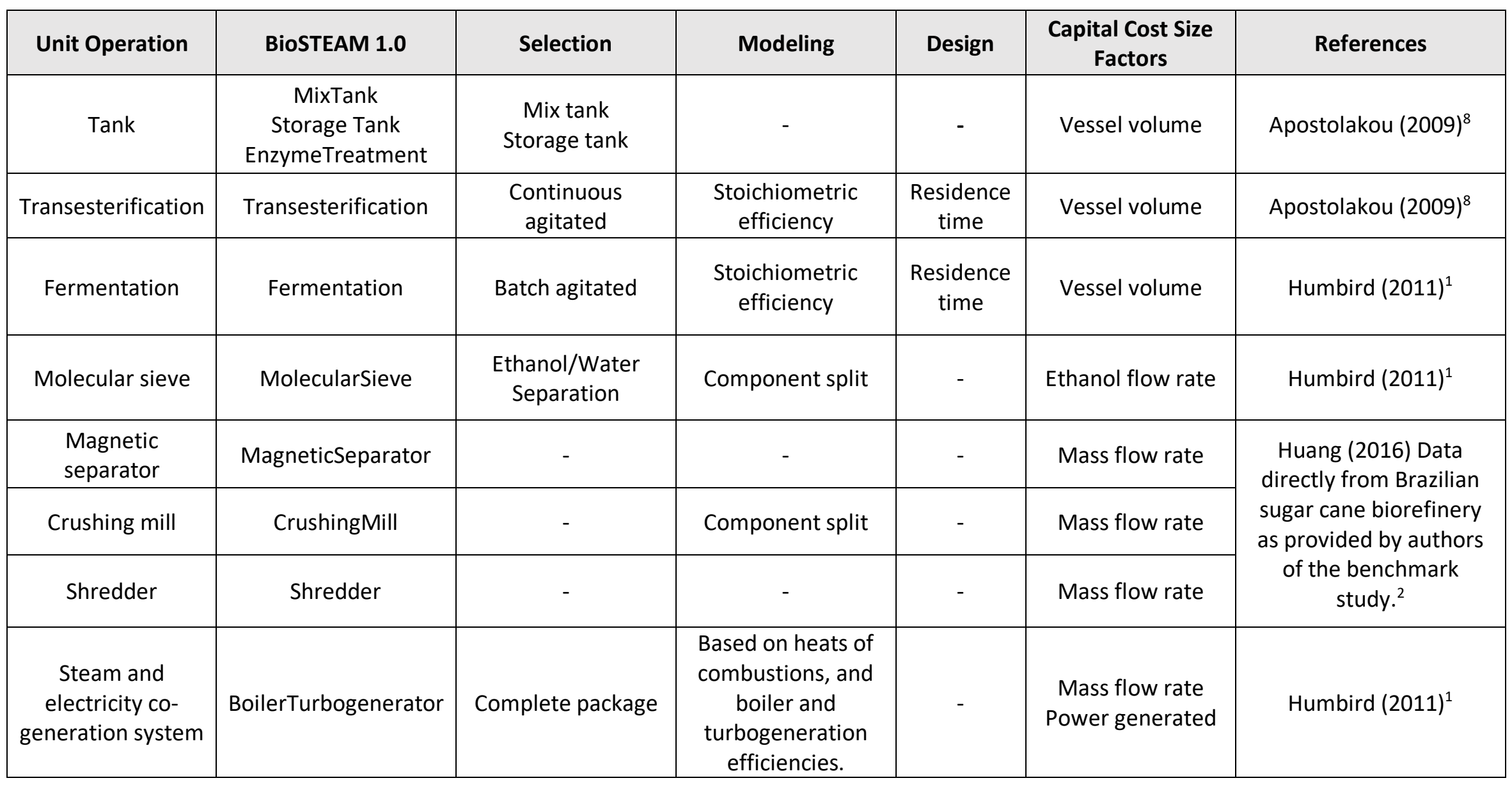




\section{Accessing Biorefinery Models and Detailed Results}

All biorefinery source code and excel results are available in the BioSTEAM Bioindustrial-Park GitHub repository, ${ }^{9}$ a standard repository for complete biorefinery models and results to foster accessibility and deeper communication within the biorefinery simulation community. The specific BioSTEAM version used to generate the results is noted for each set of results as future BioSTEAM versions may include more rigorous thermodynamic models and/or assumptions that may alter results. The excel results include flowsheets, utility requirements, design requirements, itemized costs, cash flow analysis, and parameter distributions for each biorefinery. Although the excel results can be instantaneously generated in BioSTEAM with the "save_report" method of biorefinery systems, the excel files are included to make the results more accessible. A tutorial on how to use the biorefinery models is detailed in the BioSTEAM documentation. ${ }^{10}$ 


\section{Supporting References}

(1) Humbird, D.; Davis, R.; Tao, L.; Kinchin, C.; Hsu, D.; Aden, A.; Schoen, P.; Lukas, J.; Olthof, B.; Worley, M.; et al. Process Design and Economics for Biochemical Conversion of Lignocellulosic Biomass to Ethanol: Dilute-Acid Pretreatment and Enzymatic Hydrolysis of Corn Stover; Technical Report NREL/TP-5100-47764; DOE: NREL, 2011.

(2) Huang, H.; Long, S.; Singh, V. Techno-Economic Analysis of Biodiesel and Ethanol CoProduction from Lipid-Producing Sugarcane. Biofuels, Bioproducts and Biorefining 2016, 10 (3), 299-315. https://doi.org/10.1002/bbb.1640.

(3) Oliveira, S. B. M.; Parise, J. A. R.; Marques, R. P. Modelling of an Ethanol-Water Distillation Column Assisted by an External Heat Pump. Int. J. Energy Res. 2002, 26 (12), 1055-1072. https://doi.org/10.1002/er.834.

(4) Seider, W. D.; Lewin, D. R.; Seader, J. D.; Widagdo, S.; Gani, R.; Ng, M. K. Cost Accounting and Capital Cost Estimation. In Product and Process Design Principles; Wiley, 2017; pp 426-485.

(5) Svrcek, W.Y., Monnery, W. D. (1993). Design Two-Phase Separators Within the Right Limits. American Institute of Chemical Engineers (AIChE), Chemical Engineering Progress (CEP), Fluids/Solids Handling, 53-60.

(6) Green, D. W. Distillation. In Perry's Chemical Engineers' Handbook 9th Edition; McGraw-Hill Education: New York, NY, 2018.

(7) Duss, M.; Taylor, R. Predict Distillation Tray Efficiency. 2018.

(8) Apostolakou, A. A.; Kookos, I. K.; Marazioti, C.; Angelopoulos, K. C. Techno-Economic Analysis of a Biodiesel Production Process from Vegetable Oils. Fuel Processing Technology 2009, 90 (7-8), 1023-1031. https://doi.org/10.1016/j.fuproc.2009.04.017.

(9) Cortes-Pena, Y. Bioindustrial-Park: BioSTEAM's Premier Repository for Biorefinery Models and Results; 2019.

(10) Cortes-Pena, Y. R.; Guest, J. S. Documentation for BioSTEAM: The Biorefinery Simulation and Techno-Economic Analysis Modules. (Version 1.0). 2019. 